FORMATION Formation emploi

Revue française de sciences sociales

127 | juillet-septembre 2014

Pêle mêle

\title{
Edito : S'orienter tout au long de la vie
}

Jean-Frédéric Vergnies

\section{(2) OpenEdition}

\section{Journals}

Electronic version

URL: http://journals.openedition.org/formationemploi/4235

DOI: 10.4000/formationemploi.4235

ISSN: 2107-0946

\section{Publisher}

La Documentation française

Printed version

Date of publication: 30 October 2014

Number of pages: 1-2

ISSN: 0759-6340

\section{Electronic reference}

Jean-Frédéric Vergnies, «Edito : S'orienter tout au long de la vie », Formation emploi [Online], 127| juillet-septembre 2014, Online since 30 October 2016, connection on 30 October 2020. URL : http:// journals.openedition.org/formationemploi/4235; DOI : https://doi.org/10.4000/formationemploi.4235 


\title{
S'orienter tout au long la vie
}

\author{
Jean-Frédéric Vergnies \\ rédacteur en chef
}

\begin{abstract}
Ce numéro de Formation Emploi présente plusieurs analyses qui éclairent les étapes entre études et emploi, et soulignent l'importance des processus d'orientation et d'accompagnement.

Comment se forment les choix professionnels ? Peut-on les orienter ? Olivia Chambard examine une orientation professionnelle particulière : la création d'entreprise. Elle analyse les facteurs concourant à la diffusion de l'esprit d'entreprise parmi les étudiants, suite à l'instauration de formations à l'entrepreneuriat dans l'enseignement supérieur.
\end{abstract}

Pour sa part, Catherine Didier-Fèvre montre comment les choix des jeunes dépendent largement aussi de leur cadre de vie. Elle s'intéresse plus particulièrement aux jeunes vivant dans les espaces périurbains. Ainsi, elle souligne que les différences en termes d'orientation par rapport aux jeunes qui vivent en ville ou à la campagne, ne s'expliquent pas tant par le lieu de résidence que par le milieu social et les compétences en termes de mobilité.

De nombreux facteurs influencent la poursuite d'études ; Samir Allal et Louise Ménard observent ici les dispositifs d'accompagnement (passerelles) qui ont permis à des diplômés de la formation professionnelle de poursuivre leurs études en formation technique au Québec. La qualité de l'accompagnement et le soutien au projet constituent des facteurs facilitateurs ; de même, le soutien de l'environnement et des pairs est également important mais pas toujours suffisamment mobilisé.

Pour autant, la formation, même professionnelle, améliore-t-elle l'emploi et les conditions de travail ? Loïc Trabut apporte des réponses au travers des effets de la mise en place du Diplôme d'État d'Auxiliaire de Vie Sociale (DEAVS) sur la qualité de l'emploi des aides à domicile. Au final, la valorisation symbolique et salariale liée au diplôme se réalise au détriment des conditions d'emploi. 
Enfin, Olivier Mazade s'intéresse aux difficultés de ceux qui ont perdu un emploi et aux dispositifs d'accompagnement qui leur sont proposés. L'apport d'un dispositif peut être double : les demandeurs d'emploi opèrent une distinction entre les " opportunités " proposées et les « aides à l'emploi " fournies. À travers les relations entre demandeurs d'emploi et acteurs d'insertion se construisent alors un espace d'opportunités et une latitude de décision.

bonne lecture 